\title{
La diástasis del tiempo real, entre el mito, la praxis y el éskhaton
}

\author{
LUIS CENCILLO \\ Fundación Cencillo de Pineda de Antropología \\ y Psicología. Madrid
}

\section{RESUMEN}

A diferencia del tiempo físico, que es el que miden los relojes, el tiempo vital es múltiple, porque se trata del ser mismo del viviente. En el ser humano es el existir y su vivencia de tiempo es la vivencia de su ritmo vivo existiendo. Esta vivencia se diversifica en cuanto individual o en cuanto colectiva, en cuanto subjetal y en cuanto socialmente comprometida en una praxis productora de "mundo". Se pueden distinguir varias modalidades, niveles y ritmos de tiempo (v. g., un tiempo existencial, un tiempo coyuntural, un tiempo terminal), así como diversas experiencias personalmente vividas en el tiempo, como de anticipación, o de prisa, o de estar cambiando (evolutiva o abruptamente), o de envejecimiento. El tiempo mítico es un tiempo no histórico, pero no irreal: explica los orígenes de un pueblo y de sus instituciones o un fenómeno habitual. El tiempo real vivido puede entenderse como la dinámica actual de unir un pasado que permanece como resultado de causas "pasadas" (mas operantes), tendiendo a un futuro que se va diseñando - a veces contra nuestra intención-, en un presente que es tensión y salto hacia lo todavía irreal de lo proyectado. El existir constituye una totalidad orgánica y estructurada (Gestalt), que ha de terminar por su misma naturaleza de proceso articulado.

Palabras clave: Tiempo físico, Tiempo humano, Modalidades de tiempo, Experiencia de tiempo, Tiempo mítico, Tiempo real, Totalidad del existir.

\section{SUMMARY}

Unlike physical time, which is what clocks measure, living time is multidimensional because it concerns the very being of the living. For the living human being, time is existing; his experiencing time is his experiencing the active rhythm of his existing. This experiencing varies as it is either individual or collective, subjectal or socially committed in a praxis that produces "a world." There are several modes, levels or rhythms of time (e. g., existential, junctural, terminal), as there are several - personally lived- experiences in time, such as that of anticipation, rush, changing (developmentally or abruptly) or aging. Mythical time is not an historical time, yet it is not unreal: explains the origins of a people and their institutions or a regular phenomenon. Lived real time is the active dynamics of joining a past that remains as the effect of "past" (but operative) causes, unfolding toward a future that begins to appear before our eyes — sometimes against our will-, with a present that is tension and sudden movement for a project that is still unreal. Existing is

RDTP, LIX, 1 (2004): 173-187 
an organic and structured totality (Gestalt), which will terminate because of its very nature as an articulated process.

Key words: Physical Time, Human Time, Modes of Time, Experience of Time, Myhical Time, Actual Time, Totality of Existing.

¿Qué es tiempo? ¿Es algo que se pueda perder o ganar? En primer lugar, es evidente que ha de distinguirse el tiempo de la física (que es un constructo abstracto, como todos los modelos científicos) del tiempo real, concreto $y$ bumano, lo mismo que el tiempo de cada planeta y de cada fenómeno vital (de cada especie, por ejemplo). ¿Es igual el estar-en-el-tiempo de un mineral o de un vegetal que el de un molusco o un humano? Lo más claro es definir el tiempo humano en su dinamismo constitutivo: como el repertorio de posibilidades reales que desde cada situación cambiante se nos abren. Pues lo cierto es que el tiempo es esencialmente dinamismo: el mismo ser dinámica la vida de cada especie en cada uno de sus ejemplares.

La sustancia del tiempo humano (inevitablemente personal, mas diferente en tanto sea individual o colectivo) presenta cuatro componentes:

1. Lo vivido y ya sido.

2. Las posibilidades de seguir viviendo/siendo y los cambios de ser y de vivir.

3. El instante inmediato de cada opción, para anticipar y hacer adelantar transformativamente el futuro, utilizando alguna de estas posibilidades y anulando otras; de modo que, a cada golpe de opción (o de no opción, pero sí de consolidación de un estado incoado que dejamos cuajarse, sin nuestra intervención directa), nuestro abanico de posibilidades reales cambie y, con ello, el tiempo se cualifique como expectativa, se transforme, "haga realidad" y se ofrezca como disponibilidad distinta (e incoativamente se "gane" o se "pierda").

4. Y el "salto" o momento real y presente de optar o de ingresar en una nueva situación opcionalmente creada o sorpresivamente sucedida.

Pueden vivirse intensamente las cuatro dimensiones: 1) el pasado como experiencia adquirida y solo presente en cuanto determinante, 2) el futuro como meta asumida y siempre presente en cuanto posibilidad, hacia el cual 3) se salta de situación en situación, y 4) este mismo salto, como presenteen-acto-de-superarse.

Se vive, pues, cada situación "centáuricamente": medio fuera de ella y adelantándose levemente —en forma de instante decisorio-progredientehacia la meta incoada ya en el presente. Y este dinámico presente se vive 
como intensa presión interna a optar y aprovechamiento de oportunidades cuando se hallan realmente presentes en mi entorno; y, a veces, no sólo una situación sino varias y simultáneas, y en diversos planos. O sea, que la actividad que de presente se exige puede ser intensa también y volcada en una múltiple atención hacia diversos horizontes o frentes. Para esto hay que estar entrenado.

Por diástasis y diástema — que en griego significan discriminación, alejamiento mutuo, distancia e intervalo- entendemos la característica específica del tiempo en cuanto continuo distanciamiento de cualquier momento dado (x) respecto de todos los demás.

El tiempo es un abrirse el "espacio práxico" -como una grieta progresiva de posibilidad antes inexistente- de una sucesión de instantes o de posibilidades, al ir realizando una actividad o desarrollando un comportamiento. La diástasis es un espacio accional que se produce repentinamente cada vez -en el seno de otro instante- aparentemente cerrado, al actuar en él optando por más posibilidades.

\section{HACER Y TIEMPO}

El mismo hacer "crea" el tiempo de cada posibilidad. Por eso, cuanto más se hace, más tiempo se tiene; por extraño que parezca. Uno tiene ante sí una tarde, como un bloque indiferenciado (futuro inmediato); pero, si planifica hacer en ella muchas cosas, se van articulando los momentos y acaba cabiendo todo en ella, en lo que parecía una masa monótona e indiferenciada de "tiempo igual a sí mismo".

Así, la disponibilidad de la vida misma (en cuanto futuro disponible), si se aprovecha práxicamente mientras se existe -a partir del momento presente ("desde ya")—, se va distendiendo (diástasis) y dando cabida a un número incalculable de realizaciones simultáneas en otros tantos instantes, "creados" ad hoc por la dinámica misma de la acción. Hay, pues, vidas con "más instantes" que otras. Y parece un mundo. Mas, si no se aprovecha, pasa sin sentir y, de pronto, sin advertirlo, nos encontramos con que han pasado, digamos, diez años y hemos envejecido "en el vacío" y ya no es tiempo para nada. Se acaba sin hacer absolutamente nada, sólo rutinas... Diez años resultan, una vez transcurridos, tan breves y flácidos como un minuto de aburrimiento.

Y viceversa: llega la jubilación, la sociedad nos ha imbuido los esquemas de que no hay nada que hacer ya, pero si se hace algo y se proyectan muchas cosas serias, resulta que se empieza una nueva vida, densa y relativamente prolongada bajo otro signo. 


\section{TIEMPO FÍSICO Y TIEMPO HUMANO}

La física actual oscila entre las banalidades de A. P. French (1986), quien ha llegado a la conclusión de que el tiempo físico es el que miden los relojes exactos, contando observadores fijos. Sobre el creciente perfeccionamiento de estas mediciones, con relojes atómicos reducidos al tamaño de microchips que se aproximan a los límites de la precisión útil, véase el reciente artículo de W. Wayt Gibbs (2002). Pero es éste un tiempo que cabe considerar "empobrecido". El recurso a referencias espaciotemporales para diseñar sistemas de representación de la realidad física impone la necesidad de deducir las relaciones de transformación de coordenadas entre diferentes sistemas de referencia, en los que se cuentan las relaciones de los sistemas de Lorentz. Las de la Geometría Analítica corresponden a sistemas que están en reposo entre sí, donde las únicas cosas que cambian son las meramente espaciales: el punto de arranque de las coordenadas y la orientación de sus ejes. Lo que interesa, en cambio, para aproximarse a la realidad, son las relaciones de trasformación de coordenadas entre sistemas de referencia en movimiento (los unos respecto de los otros). Tales coordenadas pueden reducirse a relaciones entre dos sistemas con ejes paralelos, en los que lo único que cambia son las posiciones de los orígenes de las coordenadas.

El hecho de que Gauss y Weber hayan destacado como magnitudes básicas la masa, la longitud y el tiempo, de forma un tanto convencional, no debe hacer creer que necesariamente lo sean. Sea cual fuere el movimiento del foco de la luz, cuya velocidad es el referente universal, la diferencia entre dos lapsos de unos mismos sucesos será la del movimiento de los relojes con que se midan. Pero el tiempo no es una magnitud inherente a las características intrínsecas de los objetos físicos, sino a sus comportamientos. La magnitud variable $t$ es inherente a todo comportamiento posible.

Se supone que el fluir del tiempo es constantemente el mismo para todos los objetos que se comportan como relojes y que están en reposo en el mismo sistema de referencia. Cuando se considera que no lo están, el hipotético observador se supone que percibe uno de ellos primero y el otro después. Y lo que separa el primero del segundo es el tiempo, que según French es lo que mide un reloj.

Los experimentos de B. Rossi y D. B. Hall con los muones de los rayos cósmicos (1941) demostraron que la relatividad del tiempo es una propiedad de la realidad física y no una relación entre los sistemas de coordenadas espaciotemporales ideados para modelizarla. Por ejemplo, la longitud que separa dos puntos dentro de un mismo espacio físico no puede ser alterada por la decisión de cambiar de sistema de referencia. No sucede lo mismo 
con el tiempo, que entre los mismos sucesos no es el mismo si va medido por relojes en reposo con el punto en que aquéllos tienen lugar, que medido por relojes que se mueven respecto del punto en cuestión y el llamado tiempo de envejecimiento que afecta a los objetos que se comportan como relojes y es el que miden los relojes que se hallen en reposo respecto de ellos. Por lo tanto, la simultaneidad de sucesos que acontecen en puntos diferentes desaparece de la percepción de observadores que no están en reposo.

La relatividad del tiempo según el estado de movimiento de observadores y de sus relojes de referencia es lo que exige la creación de la relación $x^{-}=\gamma(x-v t)$ para que, con el cambio de coordenadas a otro sistema inercial, sigan teniendo validez las constantes físicas (o "leyes") inferidas a partir de observaciones reales pero mediante un determinado sistema de referencia.

En cuanto a las audaces hipótesis de la Mecánica Cuántica - no nos vamos a detener mucho en ello, pues no es nuestra especialidad-, desde luego que en la racionalidad humana ha de haber algún elemento no-algorítmico; esto es lo que los aciertos hacen sospechar. La célebre ecuación de E. Schrödinger dice cómo evoluciona la función de onda en relación con el tiempo: si descomponemos la variable y en "estados de momento" ("tonos puros"), cada uno de sus componentes individuales se moverá a una velocidad que es $c^{2}$ dividida por la velocidad de una partícula clásica que tuviera el momento en cuestión. Es una ecuación análoga a las de Hamilton y Maxwell y supone una evolución completamente determinista de la función de onda, una vez que se especifica para un instante cualquiera. No presenta nada del indeterminismo que se le supone como característica a la Teoría Cuántica (véase Schrödinger 1984, 1985). Sin determinismo, este proceso de evolución lo llamamos $U$ ("evolución unitaria", según John von Neumann; véase Neumann y Morgenstern 1947). Pero si amplificamos los efectos cuánticos hasta el nivel clásico y "hacemos una medida", las reglas se cambian: no se utiliza $U$, sino $R$ ("reducción del vector de estado") formando cuadrados de los módulos de las amplitudes cuánticas para obtener las probabilidades clásicas. Sólo este segundo procedimiento introduce incertidumbre y probabilidades en la Teoría Cuántica. $R$ significa que las amplitudes de probabilidad se conservan en la evolución de un paquete de ondas, por ejemplo. En la Imagen de Heisenberg, el estado que se describe parece no evolucionar.

Según R. Penrose, no hay flujo de tiempo en absoluto (véase Penrose 1991, Penrose y Rindler 1984-1986). Todas las ecuaciones con resultados positivos son simétricas respecto del tiempo; pueden valer tanto en una dirección de tiempo como en otra. Futuro y pasado parecen estar físicamente en plano de igualdad: las ecuaciones de Maxwell, la relatividad general de Einstein, la ecuación de Dirac, la de Schrödinger y otras, todas permanecen 
inalterables si se invierte la dirección de la coordenada t en -t. Toda la Mecánica clásica, además de la parte $U$ de la Cuántica, es completamente reversible en el tiempo. Y todavía está abierta la cuestión de si la parte $R$ de la Cuántica es realmente reversible o no.

Según la Teoría de la Relatividad, no existe en absoluto algo como "el ahora". Lo más cercano es el "espacio simultáneo" de un observador en el espacio-tiempo (holam en hebreo, que significa a la vez "universo" e "historia"), pero nunca coincidiría el observador A con el B. Se podría, desde el enfoque $U$, considerar a $\mathrm{A}$ como en el pasado fijo y a $\mathrm{B}$ como en el incierto futuro. Mientras que, desde $R$, cualquiera de los dos sucesos observados por A y B permanecen inciertos, en tanto el otro se halla definido.

Desde la Relatividad y sus ecuaciones, sólo hay espacio-tiempo y ninguna cabida para un "futuro" inexorablemente invadido por el presente-pasado. Solamente apelando a la Segunda Ley de la Termodinámica y a la entropía subsiguiente se puede romper este determinismo que elimina el futuro contingente. Pero no vamos a entrar en ello aquí. Remitimos al lector interesado a las obras de Gregory (1981), Hadamard (1968) y Resnikoff y Wells (1973) para una información más detallada sobre los autores y formulaciones que hemos mencionado.

\section{LA DIVERSIFICACIÓN IMPREVISIBLE DEL TIEMPO HUMANO}

Si bien la física reconoce hoy un tiempo de envejecimiento intrínseco a los objetos reales, aunque pueda ser uniformemente medido por los relojes de French (aquellos cuyos intervalos regulares son idénticos entre sí), cada especie, cada clase, cada etnia y cada individuo tienen el suyo propio; y esto es en lo que ha de reparar la antropología. Aun más: por lo menos en el caso de la especie humana, el tiempo se diversifica imprevisiblemente. Ésta es la primicia que aquí ofrecemos: la diversificación cualitativa del tiempo en la especie, sistémicamente tratado.

El tiempo no ha sido todavía tratado adecuadamente en Filosofía: Heidegger y Jankélévitch tiraron en otra dirección, una vez descubierto el tiempo como tema específico y dicho que el ser es transcurrir. El análisis de la vivencia de tiempo de Husserl estuvo lastrado por el pie forzado del "Yo Puro" como sujeto trascendental de toda vivencia posible. Aquí lo vamos a hacer nosotros en el sentido no busserliano: analizaremos la vivencia de tiempo en su gran despliegue cualitativo. La vivencia de estar siendo es la unidad fundamental de nuestro estudio, vivencia de un tiempo concretamente vivido en una modalidad muy determinada y diferente de una situación - histórica o personal- a otra.

En primer lugar, el tiempo real de los organismos como constitutivo esen- 
cial de su propio transcurrir como reales $\mathrm{y}$, por otra parte, la praxis misma colectiva y el desarrollo individual (caracterial y ético) - bien sea realizativo o frustrante (por integración de los impulsos), bien se trate de las previsiones de futuro, de los horizontes existenciales de situación: "masa de acontecimiento", o de sistemas de referentes abarcativos (cada vez adoptados)—, dan lugar a otros tantos modos de temporalidad real y significativamente vivida como cualitativamente diferente en sus varias dimensiones, cuya realidad se comprueba en que causan (pues no son sólo específicas formaciones culturales) efectos físicos.

No hay, pues, como pareció sugerir inintencionadamente la física clásica, objetos "en reposo" -que puedan llegar a moverse y establecer relaciones de tiempo con otros objetos, como lo miden los relojes de French- sino que la misma consistencia y sustancialidad de los cuerpos reales y vivos es ya tiempo. Sus propiedades equivalen a las condiciones para que el tiempo se dé: el tiempo interno es constitutivo del propio desarrollar y eliminar posibilidades, en cada sujeto viviente. Es en lo que el ser consiste. No sólo el existir.

Así que se es tiempo, y de muchas maneras (que Heidegger no sistematizó). Digámoslo lapidariamente: Pluraliter et pluribus modis tempus evadimur...! (evadimur no significa "evadirse" sino "resultar que se es").

\section{VIVENCIAS PERSONALES Y MODALIDADES TEMPORALES}

Los procesos biológicos, los procesos psíquicos (siempre personales) y los procesos práxicos (colectivos) son esencialmente tiempo y constitutivos de tiempo. Ahora bien, ¿de un mismo tiempo?, ¿de un tiempo uniforme $y$ bomogéneo (el que muchos físicos creen que miden los relojes)? No lo creemos así.

En la especie humana, su transcurrir histórico-productivo de mundo, su praxis, parece diversificarse en otra serie de formas objetivas de temporalidad.

Se pueden distinguir las vivencias personales y modalidades temporales (de transcurrir el individuo, el grupo y los sucesos) que pueden diversificarse en otros tantos modos "tiempo":

\section{A) Modalidad vulgar.}

1. existencial (individual),

2. epocal,

3. evenemental,

4. práxico-colectiva. 
B) Modalidad personal decisoria:

5. coyuntural o "kairótica",

6. interna (cumulativo ya-sido),

7. proyectual,

8. posibilitante o de futuro.

C) Modalidad extrabistórica y anagógica:
9. onírica
10. mítica,
11. madurativa,
12. terminal,
13. escatológica.

\section{FORMAS DE ESTAR SIENDO}

1) El tiempo mismo -el estar siendo-consiste en una amplificación: una diástasis o despliegue del ente, que es (en forma de diferentes momentos de su proceso de realizar posibilidades).

2) El hombre que existe en forma de agente de una praxis cultural y productiva va creando (o se le van creando) los diversos ámbitos de tiempo ya mencionados.

3) También existe -y es él mismo- como el reo amarrado a la cola de cuatro caballos (amplificándose desde dentro, obligado a hacerse mayor de lo que era: diástema).

4) Para admitir nuevos ya-sido y aplicarse a nuevas tareas, sin - a lo mejor- poder abandonar las anteriores.

(La neurosis es un negarse a esta amplificación, a veces casi brutal, a que el ser tiempo transcurriendo nos obliga.)

En otras palabras: ser sujeto existente - ser "hombre" concreto- implica un estar constantemente desplegándose "diastemáticamente" como creador de instantes situacionales - $-\mathrm{y}$ de constelaciones de acontecimientos - vivenciados como "existir" en forma de ritmos y caracteres (de la vivencia de tiempo):

- proyecto, desarrollo,

- kairós, opción,

- avance, recuerdo,

- anulación, cambio,

- reinstauración, reasunción,

- cumplimiento, afirmación

- y negación. 
Todas estas formas de estar siendo son reales, pues se perciben como vivencias que repercuten realmente en el modo de existir - retroproyectivamente, hasta en el pasado- y en los estados psíquicos: como la creatividad, como energía disponible y como "gestáltico" incremento de si-mismo.

Se producen entonces experiencias personalmente vividas en el tiempo de:

- creación o auto-posición actual,

- anticipación (onírica, videncial),

- estar cambiando (evolutiva o abruptamente),

- prisa (en la que el tiempo se volatiliza),

- tedio (en el que el tiempo se dilata y "no pasa"),

- bloqueo (estar paralizado en el desarrollo psicosocial) y, finalmente,

- vivencia de envejecimiento y de terminalidad (que es cualitativamente distinta).

\section{CUALIDADES DE LA TEMPORALIDAD}

Hay que distinguir las cualidades de los modos de temporalidad. Aunque no sean físicamente medibles, las cualidades sí son en sus efectos realmente eficientes (alem. wirklich). (Prescindimos de los estados alterados de conciencia: confusionales, inversivos, lagunares, "estar en otro tiempo", regresionales, algunos de los cuales pueden provocarse por sugestión o espontáneamente y resultar terapéuticos.) Las cualidades que percibimos —según circunstancias y situaciones- son diversas, como:

1. Densidad diferente: tiempos en los que parece estar sucediendo "mucho" —o a la vez o sucesivamente, pero en estrecha interconexión-, mientras que otros tiempos se pasan ligeramente. Un efecto paradójico: los tiempos "ligeros" o "enrarecidos" se hacen largos y pesados, mientras que los densos se hacen breves.

2. Hondura: vivencias en las que parece sumergirse el sujeto en otra dimensión, más "honda", o más lejana de la conciencia (hasta llegarse al ámbito onírico), pero a propósito de un único tema, experiencia, problema o contenido de conciencia; y otras vivencias que transcurren en el plano de la práctica cotidiana y trivial.

3. Multivalencia o simultaneidad de planos: suele ocurrir con el plano escatológico y el de la cotidianidad.

4. Diástasis propiamente dicha: estiramiento o amplificación en el horizonte de capacidad de vivencia y de comprensión entre ámbitos cualitativamente diferentes; por ejemplo, lo estético y lo místico, o lo filosófico 
—vivido- y lo práctico, o lo actualmente político y la visión perspectival histórica; lo particular (íntimo y estrictamente personal) y lo universal /colectivo, o la vividura ajena y la propia fusionadas en el amor.

\section{FENOMENOLOGÍA DE LOS MODOS DE VIVENCIA}

El tiempo es, en primer lugar, existencial (individual): se trata del tiempo vivido en concreto y, por lo tanto, experimentado como transcurrir duradero (francés durée) en la acción y en el salto constante de la Zeitigung, ocupado en y con... (el "mundo") y el mundo de cada cual... (alem. Jemeinigkeit: literalmente, "cadaunidad").

Hasta ahí, el existencialismo del segundo cuarto del siglo xx; pero, además, hay otras formas muy variadas e inesperadas de temporalidad vivida en grupo e individualmente, a saber:

1. Una temporalidad práxica (además, común o simultánea) o la oportunidad de hacer algo; el espacio de un comportamiento útil, obligado: la dedicación aquí y ahora a una tarea.

2. Epocal, colectiva e bistórica. Es el tiempo vivido en grupo formalizado, con sus referentes propios y fijos, algunos de los cuales son temporales: fechas significativas, semanas, años, siglos (según una era), conmemoraciones, plazos, reinados, oportunidades colectivas ofrecidas por una revolución o un reinado.

Evidentemente, es distinta la vividura del tiempo individual —del tiempo subjetivo-, del tiempo familiar y del tiempo colectivamente vivido con sus referentes de grupo y de identidad nacional o política. Pues el tiempo se va amueblando y articulando con fechas, calendarios y conmemoraciones de referentes históricos o religiosos.

3. Coyuntural, que puede ser kairótica. Es el tiempo como instante decisivo. El "instante" es el momento que aquí y ahora urge, porque en él va a pasar o hay que realizar algo según aquello de "cada cosa tiene su tiempo". Pero el momento coyuntural añade el matiz de oportunidad que pasa, de tránsito de un instante a otro en el que ya será tarde para optar o decidir. Es un instante cualificado como oportuno. Precisamente hay una perturbación de la vida insconsciente, que obliga a no ver el momento oportuno de decidir o de intervenir en algo y hace que siempre se llegue tarde o se precipite la decisión cuando "no era oportuno".

El kairós es todavía más cualificado: no sólo es el momento oportuno sino la ocasión providencial única para tomar una decisión, para optar o para comenzar una actividad de gran trascendencia.

4. Escatológica: la modalidad de tiempo más sorprendente; podríamos 
definirla como el tiempo anagógico o tiempo existencial "prendido" del fin teológicamente concebido. (Es especialidad de la vida cristiana, que tiene que ser escatológica para tener sentido y aliciente.) Lo peor del existir actual es que hace mucho que se olvidó la dimensión escatológica de la vida. Y aun cuando antes — convencionalmente - se hablase de "escatológico", la vida era dura y aburrida por vivirla en realidad así, mundanizada.

5. Evenemental (semejante al tiempo histórico y colectivo, pero en acción productiva de cambios) o duración de un proceso o acontecimiento importante. Puede ser de duración predeterminada por su naturaleza, un tiempo o plazo requerido para madurar algo o alguien: como estudiar una carrera, celebrarse unas elecciones, votarse una ley o reformar una institución. Y todavía más, el tiempo de acontecimientos impresionantes para toda una sociedad, que marcan un antes y un después: como la Guerra Civil de 1936, el ataque a las Torres Gemelas de Nueva York en 2001 o los recientes atentados del 11-M en Madrid. Todo lo cual son eventos (inglés, events; francés, evenements) que van formando "historia". Es un tiempo cualificado, "trascendental", crucial; pero limitado al logro de un efecto colectivamente interesante, que se ha de sumar a otros, o al cual otros han de sumársele, todos lo cuales han requerido cada uno su tiempo evenemental.

6. El tiempo mítico, al que algunos antropólogos, como M. Eliade (1999), se refieren como "in illo tempore": un tiempo no histórico, pero tampoco "irreal", sino de alguna manera válido (por no llamarle "real"). Es el tiempo de los hechos primordiales que explican los orígenes de un pueblo, una religión, o un evento o fenómeno habitual. Es cierto que los orígenes reales y práxicos no fueron fácticamente así; pero, como éstos se ignoran, se ha encontrado en el mito un fundamento explicativo válido (alem. wirksam) para enlazar la institución actual o la identidad del grupo con un referente comprensible, que estabiliza la autoconciencia del mismo. Se crea así una cuasi "historia" o perspectiva de los orígenes que, más que fáctica, resulta filosófica y contiene el producto de una sabia reflexión del grupo acerca de su identidad y de sus peculiaridades. Las ciencias serían mitos con notación canónica y matemática.

7. Terminal o época en que un sujeto envejecido o enfermo no puede contar ya con más tiempo por delante: el tiempo existencial se le termina, acaba su plazo para vivir y realizar proyectos y tareas. No tiene proyecto ni horizonte práxico por delante: es esto precisamente lo característico de este tiempo terminal, que puede o durar más o menos, y ser como tal percibido por el interesado, o no. Sus proyectos subjetivamente válidos dejan de serlo - pues no van a poderse realizar, ni tiene nada que hacer en la práctica- y, sin embargo, pudiera vivir bajo la pura ilusión de mantener la tensión existencial y huir de una conciencia inmediata del ser para la muer- 
te. Se puede entender entonces lo que, en nuestra opinión, sería la gran mentira de los monitores de la llamada "Tercera Edad", que pudieran comentar del anciano(a) que "tiene muchas ganas de vivir" y estar proyectando viajes, coqueteos, enlaces o negocios; pero los hechos demuestran que, sin saberlo o sin quererlo saber, está en su tiempo terminal: no le queda tiempo. Puede por eso decirse que le estarían engañando miserablemente. Sus supuestas posibilidades reales de seguir existiendo, de hecho o de derecho, ya no tienen validez ni lugar: pues no va a poder llevarlas a cabo, por mucho que las planee; "vive de mentiras". (No me gustaría a mí ser víctima de tal.ocultación, que priva de la lucidez de morir.)

Ahora ya podemos describir las modalidades más familiares del tiempo:

8. Interna: tiempo cumulativo en retención o ya-sido, y de otro lado proyectual. Es semejante al anterior, pero no como sujeto práxico sino como Yo comprometido por su realización decisional, como proyecto asumido o en construcción, onírico.

9. El tiempo madurativo, que transcurre como un Yo que existe y, al existir, pierde y gana; pero la resultante es el densificarse de si mismo tanto por la pérdida como por el logro: un irse identificando a considerables plazos (decenios) como idéntico y distinto: lo ya-sido + lo en curso + el proyecto más o menos logrado, todo ello como étalage de uno mismo en cuanto existente y real.

La realidad de cada uno es su hacerse uno mismo dejando de serlo cada periodo para ser diferentes en lo mismo.

10. Tiempo posibilitante, o tiempo como conjunto de posibilidades actuales y sucesivas; pues ésta es la razón de que nos sintamos "transcurrir": pasamos de una posibilidad a otra o, en un único instante, intermitentemente alternamos la actualización de diferentes posibilidades. Es el futuro. Pero, ¿el futuro es real? Sí que lo es, si bien en cuanto haz de posibilidades ofrecidas que determinan el presente ("masa de acontecimiento"). En cuanto presente/futuro, el tiempo no es nada determinado y fijo (aun a pesar del famoso "genoma"); por el contrario, es móvil y se va trasformando y cualificándose o descalificándose como posibilidad real o virtual, como posibilidad desperdiciada y abortada, como omisión y tarea no cumplida, o como comienzo de nueva situación y productiva, o final de una utopía. En cada instante presente, al optar y al emprender un cambio de actividad o de situación, el futuro cambia y cambia parte del tiempo en cuanto posibilidad. El presente es igualmente elástico, puesto que es el momento de optar $y$ decidir.

Y el pasado, que no es en sí modificable, por lo menos es diversamente valorable según se enfoque y se alumbre con criterios de uno o de otro tipo. 
Y hasta se trasforma emocionalmente para cada generación; compárese la Edad Media para los románticos con la oscura memoria ilustrada de la misma, por ejemplo.

\section{EXISTENCIA Y POSIBILIDAD}

En otras palabras, nuestro existir flota, oscila y resbala entre todas estas modalidades de posibilidad: de valoración y de asunción, de opción y de cambio de horizonte de posibilidad. Esto es existir viviendo.

Pero todo esto sucede y se hace para "algo". Y es en este "algo" donde nos podemos equivocar. $\mathrm{O}$ no acertar en absoluto a vivir. Hay muchos que no aciertan a vivir; y unos se aturden con el éxito, mientras que otros se deprimen con sensaciones de estar fracasando siempre. Y ello, no por influencia manipulativa de nadie sino por descuido y torpeza propias. Se cuida la línea, se cuida "la imagen", se cuida la dieta y hasta el cutis y las uñas, o la frecuencia de las deposiciones; lo que nunca se acierta a cuidar es la existencia. Es trágico que lo más importante, lo más inmediato, lo que dimana de o contribuye a nuestra propia entidad consistente (que no son los huesos ni los tendones) sea lo que la mayoría no acierta a comprender ni a elegir o a ser. Para eso estamos los terapeutas, siempre que seamos amplios y multifocales. La mayoría ex-iste, simplemente (esto es, salta de la nada); pero tal vez no llegue nunca al ser lo que se es, el que se tiene que ser, al ser uno-mismodesde-si-mismo, el ser plenamente lo que se podía todavía ser.

Todo sucede en nosotros a medias. Hemos venido siendo a medias y acabamos de existir también a medias, engañándonos y sin acabar de morir como una persona ha de terminar su estar-en-el-mundo, es decir plenamente, dándose lúcidamente cuenta de lo que le está pasando y adoptando la actitud que, desde su desfondamiento radical y desde su sistema de referentes últimos ${ }^{1}$, crea deber adoptar o haya adoptado como por casualidad.

"Matar el tiempo", "perder el tiempo": son expresiones que asustan. Pues el tiempo es siempre indispensable y no se puede ni matar ni perder. Puede llegar a hacer mucha falta y sucede como con el dinero. El tiempo es enormemente más importante que el dinero y, en cambio, suele comparársele con él o con el oro para ponderar su gran valor. Pero el tiempo vale más que el dinero y el oro, porque es realmente nuestro estar siendo, concreto

\footnotetext{
${ }^{1}$ Todo sujeto tiene un sistema de referentes últimos, sólo que hay muchos modelos. Pero no es posible para alguien que no haya en el trasfondo de sus ideas acerca del mundo una filosofía más o menos simplista o ideológicamente prejudicada; de la cual ni siquiera es consciente, pero de la que, de no ser una personalidad muy confusa, se puede por mayéutica inferir el sistema elemental de mundo, del que vive.
} 
y real, dinámico y operativo. Así que quien existe sin decidirse a actuar lleva un existir de sombra o se siente ser una "cosa entre las cosas" (como suponía C. Lévi-Strauss que era la mente humana, toda mente humana... ¡Desdichado siglo $\mathrm{Xx}$, que para ser científico se sentía obligado a matar al hombre!). Lo que con el dinero sucede es que, por mucho que se tenga, al menor descuido se ha perdido más de lo que se preveía. Con el tiempo, lo mismo o más. Pero con la desventaja de que, por mucho tiempo que quede, puede ya no ser apto para ciertas cosas, como prepararse a alguna tarea o adquirir cierta capacidad.

La vida de un anciano, después de su jubilación, puede durar todavía 25 ó 30 años; pero ya no es tiempo para muchas cosas, por más que los de las asociaciones asistenciales se crean en la obligación de hacer creer que sí es, con lo cual les roban la identidad. Desde luego que ya no es tiempo para formarse y adquirir nuevas capacidades profesionales, aunque para esto habría de durar sólo 3 años (entre los 25 ó los 30 que le queden por vida a determinado sujeto senescente) ${ }^{2}$. Y precisamente la ancianidad -que, como decimos, puede ser ahora muy prolongada - tampoco se cuida: sólo se la distrae de su ser genuino y, así, como decíamos, se la engaña. Lo cual hace nuestro entorno -tópicamente dicho: "la sociedad"- y no pocas veces las personas que dicen "querernos", pero cuyo inconsciente más bien desearía que desapareciéramos ya pronto. Una ancianidad prolongada ha llegado a ser una desgracia. Hay que tomar conciencia de que este mundo no puede seguir siendo nuestra morada estable: la Gestalt ("totalidad estructurada") existentiva se ha consumado con la edad, y nada tiene de trágico que el fin naturalmente suceda y la Gestalt se dimensione de otros modos posibles.

Hay agnósticos que afirman, al llegar a cierta edad, que afrontan la muerte "con valor". Sin embargo, ¿por qué hace falta tanto "valor" cuando se han relativizado tantos valores? Si es la Nada lo que nos espera, no hace falta "valor" para dejar absolutamente de ser. Y si es el Todo, al modo cristiano y tal como hoy se le concibe (no como un severo juez, que condena por nimiedades), dejar este mundo y esta vida es pléroma, impleción.

No creemos que nadie intelectualmente cultivado admita, como seria, si así lo hiciera, la "horterada" de la tercera vía de la "reencarnación". Filosóficamente es absurda $\longrightarrow$ extremadamente difícil de admitir-, pues supone un estado contradictorio del $Y o$, que es autoconciencia e identidad única, incapaz de olvidarse de sí, un estado en que se vea obligado a más de lo mismo, pero olvidado de sí y con otra identidad, o muchas identidades sucesivas. Esto sólo puede pensarse en culturas arcaicas en las que el individuo, como Yo, no tiene todavía entidad ni conciencia de sí. ¿Qué se reencarnaría

\footnotetext{
${ }^{2}$ Nos remitimos a nuestro Abordaje terapéutico de ancianos (Cencillo 1999).
} 
entonces? El Yo personal no puede ser, y la "energía" ya sabemos que puede "transmigrar", aun en vida sin más misterio.

¿O es que aun los agnósticos tienen dudas acerca de que no todo acaba y se imaginan vagamente un posible destino demasiado incierto?

Para esto sí que hace falta valor, y mucho ${ }^{3}$.

\section{BIBLIOGRAFÍA CITADA}

CENCILLO, L. 1999. Abordaje terapéutico de ancianos. Madrid: Ediciones Fundación.

-. 2000. Creatividad, arte y tiempo. Madrid: Syntagma Ediciones.

-. 2001a. Tiempo ganado, Tiempo perdido. Madrid: Syntagma Ediciones.

- 2001b. Cómo no bacer el tonto por la vida. Bilbao: Desclée.

-. 2002a. El estado sin dolor. Madrid: Syntagma Ediciones.

- 2002b. Homosexualidad y paradojas sociales. Madrid: Syntagma Ediciones.

-. 2002c. Guía de Perdedores, perdidizos y perdidos. Madrid: Syntagma Ediciones.

ELIADE, M. 1999. El mito del eterno retorno: arquetipos y repetición [1951]. Madrid: Alianza Editorial.

FRENCH, A. P. 1986. Einfübrungskurs der Physik. Braunschweig: Vieweg.

GREGORY, R. L. 1981. Mind in Science. Londres: Weidenfeld \& Nicholson.

HADAMARD, J. 1968. Ciencia y método. Madrid: Espasa Calpe.

Neumann, J. Von, y O. MORgenstern. 1947. Theory of Games and Economic Behavior. Princeton: Princeton University Press.

PenRose, R. 1991. La nueva mente del emperador. Madrid: Mondadori.

Penrose, R., y W. Rindler. 1984-1986. Spinors and Space-Time. Cambridge: Cambridge University Press.

ReSNiKOFF, H. L., y R. O. Wells, Jr. 1973. Mathematics in Civilization. Nueva York: Dover.

Rossi, B, y D. B. HALl. 1941. "Variation of the Rate of Decay of Mesotrons with Momentum". Physical Review 59: 223-228.

SCHRÖDINGER, E. 1984. ¿Qué es la vida? Barcelona: Tusquets.

-. 1985. Materia y mente. Barcelona: Tusquets.

WAYT GiBBS, W. 2002. “Ultimate Clocks”. Scientific American 287 (3): 68-75. (Traducido al español en Investigación y Ciencia, noviembre de 2002.)

\footnotetext{
3 Tratamos más extensamente de todas estas cuestiones en otros trabajos: Cencillo 2000, 2001a, 2001b, 2002a, 2002b, 2002c.
} 